\title{
Envío, acontecimiento y catástrofe. La correspondencia entre Heidegger y Derrida.
}

Sending, event \& catastrophe. The correspondence between Heidegger and Derrida.

\author{
Marco Antonio Núñez Cantos' \\ Universidad Nacional de Educación a Distancia, España \\ Recibido 27 noviembre 2020 · Aceptado 31 enero 2021
}

\section{Resumen}

En el presente artículo nos proponemos examinar, en primer lugar, la deconstrucción de la noción heideggeriana de Ereignis como "envío del ser" mediante su desplazamiento al ámbito de la tecnología de "lo postal". En segundo lugar, veremos las consecuencias que se derivan de inscribir un concepto ontológico en contexto reglado por la alteridad que escapa a los dominios del logos, tanto para una visión genealógica de la historia intelectual, como a la hora de ilustrar la naturaleza de la compleja de la relación entre ambos filósofos.

Palabras clave: Heidegger, Derrida, Ereignis, Envío del ser, Postal

\section{Abstract}

In first place, our porpose in this paper will be to examine the displacing carried out for Jacques Derrida of the Martin Heidegger's concept of Ereignis as "Sending of Being", from the ontology to the realm of postal technology. Secondly, we will see the consequences that derive from inscribing an ontological concept in a context governed by alterity, both for a genealogical view of intellectual history, as well as when illustrating the nature of the complex relationship between the two philosophers.

Keywords: Heidegger, Derrida, Ereignis, Sending of Being, Postcard 


\section{1・Introducción}

La peculiar correspondencia entre Martin Heidegger (1889-1976) y Jacques Derrida (1930-2004) se concreta en la transposición que este último realiza de las cuestiones y nociones de carácter ontológico al ámbito textual. Heidegger se había propuesto en Ser y tiempo la Destruktion de la filosofía occidental, es decir, el desmantelamiento de la metafísica de la presencia responsable del olvido de la diferencia ontológica. No obstante, juzgará que su obra sigue en exceso lastrada por determinaciones de naturaleza metafísicas. En adelante, se propone repetir la analítica del Dasein de forma más originaria dando un "paso atrás" (ein Schritt zurück), a fin de remontar hacia lo que había quedado sin pensar, la diferencia entre el ser y los entes, y, en consecuencia, desplazando su investigación hacia la noción de Ererignis.

Para Derrida, la pregunta por el ser y la atención a la diferencia ontológica, tal como las plantea Heidegger, son imprescindibles para la tarea de deconstrucción de la metafísica. Así, en un primer momento, parece dar cumplimiento a un proyecto que, sin embrago, juzga inconcluso por no haber extraído todas las consecuencias de la problemática temporal por él planteada. En efecto, si bien Heidegger localiza una diferencia estructural en el origen que "destruye" la esencia del ser como presencia, posteriormente hace intervenir una reunificación (legein), como pone de manifiesto el empleo recurrente en el vocabulario heideggeriano de palabras con el prefijo "ge-", cuyo semantismo connota una reunión o agrupación (Geviert, ge-eignet, Ge-stell, Gemiit, Gedichtnis, Geist, Geschick). Derrida se pregunta por la posibilidad de una différance en el origen que sea irreductible a toda reunificación y opere como condición de posibilidad para que haya tal cosa como un Geschick del ser. Esta es la premisa que orienta su lectura del Ereignis heideggeriano y su abordaje desde la economía de "lo postal" lo que le permite cuestionar la co-pertenencia entre las ideas de "origen", "unidad" y "destino", revelando un origen derivado y múltiple, en definitiva, un "no-origen" refractario a la apropiación por el legein del logos.

En primer lugar trataremos de determinar en qué consiste el concepto de Ereignis al que Heidegger otorga una resolución identitaria y unificadora en relación al envío del ser, así como una determinación ulterior en diversas épocas. En segundo lugar, continuaremos analizando la trans- 
posición que la lectura derridiana realiza del Ereignis a una tecnología de "lo postal" regulada por la différance, donde su unidad constitutiva ha sido siempre ya descentrada y transformada en una red que no puede asegurar la indivisibilidad de su origen, ni la certeza de su destino, considerando que la "época de la metafísica" en su deriva tecnológica es a la vez más general y originaria que la economía restringida del ser. En tercer y último lugar, a través de la operación anteriormente referida, se cuestiona la propia noción de "historia de la filosofía" desde la perspectiva de la recepción "catastrófica" del pensamiento de Heidegger, como remitente, por parte de su destinatario, Derrida, toda vez que al trastocarse el esquema de legador/ legatario basado en un paradigma genealógico, la herencia de Heidegger se borra en el interior de su misma aceptación.

\section{2・El ser como Ereignis}

Martin Heidegger adopta en Aportes a la filosofía. Acerca del acontecimiento, un nuevo camino especulativo en relación a Ser y tiempo, que supondrá el abandono de la analítica del Dasein y el comienzo del pensamiento del ser a partir de un Ereignis" caracterizado como "[...] el esenciarse del mismo ser [Seyn]" (Heidegger 2011a 24). Pensar el ser como acontecimiento-apropiador no implica que nos encontremos ante una especie o género del ser en continuidad con el ser de una filosofía que lo había determinado como eidos, energeia, actualitas o Wille zur Macht. El ser es pensado ahora como el estar y dejar estar presente que se da en el destino: "[...] como un dar, en el que lo destinante mismo se retiene y retira en el retenerse del desocultamiento"

1 Dina V. Picotti C. en una nota al pie de los Aportes a la filosofía (2011a), justifica su traducción de "Ereignis" por "acontecimiento" y "Er-eignis" por "acontecimiento-apropiador", porque el autor, al separar el prefijo, acentúa el sentido de apropiación que quiere dar a la palabra. Por su parte, Manuel Garrido en la introducción de Tiempo y ser (2013a), señala que el prefijo er- está semánticamente investido de un valor intensivo, y el lexema eignis retiene la presencia de la voz eigen, que significa "propio", de este modo, añade a su significado ordinario de "acaecimiento", "suceso", "acontecimiento" o "acontecimiento", el de "apropiación". Ello provoca vacilaciones entre los traductores, algunos de los cuales optan por no traducir el término para no restringir su polisemia. Hechas estas aclaraciones, nosotros, optaremos por mantener el término en alemán. 
(Heidegger 2013a 51). Ese dar que da su don mientras se mantiene retirado, lo denomina Heidegger: "envío" (das Schicken). Ereignis consiste entonces en el Geschick des Seins (envío del ser) entendido como un "advenimiento a la presencia" que se mantiene retirado y con el que destruye la autoridad del presente que determina el sentido del ser, para pensar la presencia del presente entendida como el el dejar-desplegarse-en-la-presencia (das Anwesen-Lassen), donde es la presencia misma, el ser mismo, el que se despliega. El dar se manifiesta con respecto al ser como destinar y como unidad de todas las destinaciones del ser como Anwesen.

Más tarde, Heidegger formula el Ereignis a partir de la co-pertenencia del ser con el Dasein en lo que es una alternancia de donaciones y sustracciones, manifestaciones y ocultamientos, que escancian las "épocas" de la historia entre un primer comienzo griego y otro comienzo anunciado por el paso del "último Dios" y preparado por los "advenideros". Este es el modo en que el ser se destina al hombre haciéndolo acaecer y apropiándoselo en una relación de correlación recíproca. En "El principio de identidad" leemos:

La mutua pertenencia de hombre y ser a modo de provocación alternante [...] de la misma manera que el hombre es dado en propiedad al ser, el ser, por su parte, ha sido atribuido en propiedad al hombre. [...] De lo que se trata es de experimentar sencillamente este juego de propiación en el que el hombre y el ser se transpropian recíprocamente, esto es, adentrarnos en aquello que nombramos Ereignis. (Heidegger 2013b 85)

El hombre tiene su lugar en el Ereignis y participa en él. En el movimiento del Ereignis en que se produce la apropiación del ser (como Anwesen) y del tiempo (como región de lo Abierto) en lo que tienen de propio, es conducido a lo que le es propio, a saber, estar situado en el claro (Lichtung) del ser. Ereignis hace advenir la co-pertenencia del ser y del hombre como proximidad inseparable de ambos.

Por último, el Ereignis recibiría una tercera y última determinación a partir de su relación con el tiempo: "A lo que determina a ambos, ser y tiempo, en lo que tienen de propio, esto es, en su recíproca co-pertenencia, lo llamamos: el acontecimiento" (Heidegger 2013a 47-48). El acontecimiento es un dar, enviar, proporcionar y constituir en lo suyo propio al 
tiempo. En el proporcionar el pasado se da un ya-no-presente, una negación del presente; en el alcanzar el futuro se da un aún-no-presente, una retención del presente. De este modo, siempre estamos en un presente que en parte se oculta negando la prioridad otorgada por la tradición metafísica. En cualquier caso, los modos en los que el ser sobreviene a la desocultación tienen un sello epocal, el envío del ser es visto como un despliegue temporal de épocas como epojés (suspensiones del ser) en cuya secuencia metaléptica de desplazamientos, el ser es transmitido en su borrarse en las diversas modificaciones del revelado. La noción de temporalidad comprende la época como parte de una colección de relaciones en las que el ser es constituido como horizonte temporal de correspondencias entre el es gibt Sein y el es gibt Zeit. Si el envío del ser constituye una revelación y una borradura de forma conjunta, debe ser también considerado en términos de una correspondencia de momentos cuyo Ereignis es unbestimmt (indefinido), y su opuesto, Ent-eignis (desapropiación), indica la época en la que el ser se sustrae. Esta sustracción o retirada es en sí misma una expropiación que ocurre en el interior de la apropiación de correspondencias manifiestas en el envío del ser: Das Ereignis ereignet.

De modo que las nociones de "envío" y "epojé" permiten a Heidegger postular una articulación alrededor las diversas épocas del ser, donde "época" no designa en primer lugar un cierto periodo histórico, sino que hace alusión a las características del envío mismo. El retenerse o retirarse en favor de las varias manifestaciones del don, pauta el destino del ser o de su apropiación, que es también siempre una desapropiación, nombrando al ser en relación a su descubrimiento de los entes y organizando nuestra relación con ellos. Así, para Heidegger, pensar el ser consistirá en reconocer la estructura originaria subyacente en cada expresión histórica, esto es, los modos en los que el ser se des-oculta y es determinado, dando lugar a las formas particulares en las que en cada época se presencian los entes.

\section{3- El destino del ser y lo postal}

Derrida pondrá en cuestión que los diversos modos en los que el ser viene a la desocultación (1) sean parte de una sola destinación y (2) que estos modos adquieran una determinación epocal, es decir, que el ser como don 
se retenga en cada una de las determinaciones o épocas que configuran su historia como ser conjunto destinado por el envío originario. En realidad ambas objeciones remiten a la interpretación de Heidegger del Schicken sobre la base del Geschick, el destino, que establece una relación de identidad entre ambos.

Si una época no es un periodo histórico, sino la huella fundamental de la destinación, el An-sich-halten de la donación que siempre se borra a favor de sus dones, entonces estamos ante diversas determinaciones de un ser que sería siempre el mismo y que tendría lugar fuera de ellas, un "ser transepocal". Los diferentes modos en que el ser ha sido determinado a lo largo de la historia, reflejan de este modo los cambios que han tenido lugar en las diversas concepciones metafísicas del ser como acontecimiento-apropiador (cf. Heidegger 2011b 111). Cuando Platón representa el ser como idea, Aristóteles como energeia, Kant como "posición", Hegel como "concepto" y Nietzsche como "voluntad de poder", están dando respuesta a los diversos envíos del ser, cada filosofía se elabora en función de las peculiaridades de una determinada destinación del ser. Razón por la que Herman Rapaport (104) considera que las distintas nociones del ser son "metalépticas", porque a partir de ellas se transfiere la cuestión del ser y constituyen su historia. Una época no es la modificación de un ente, pero se anuncia por medio de un envío del ser que se desoculta ónticamente como presencia. Entonces, el ser-conjunto del envío originario llega hasta sí mismo en la presencia, incluso si hay disputa (Zwiespalt) en la época griega entre Mundo (Welt) y Tierra (Erde) (Heidegger 2015 31), entre el mostrar y el ocultarse, finalmente, esta división acaba por reunirse en el legein. Es decir, la presencia se salva asegurándose en una indivisibilidad de lo destinal reunida en el envío, con lo que Heidegger no hace más que ofrecer una resolución identitaria y unificadora en la noción de Ereignis, solo así puede distinguir diversas épocas:

[...] al menos hay (es gibt) un envío. Al menos se da un envío, el cual está en conjunción consigo mismo; y esa conjunción es la condición, el ser-en-conjunto de lo que se presta a ser pensado para que una figura epocal -aquí la de la representación- se destaque en su contorno y se coloque con su ritmo dentro de la unidad de un destinarse, o más bien de una destinalidad del ser. 


\section{(Derrida 2017 143)}

Donde la destinación y el envío serían siempre unitarios a causa de este auto-envío, un envío de lo mismo. De este modo, abordando el sentido heideggeriano de los términos Geschichte-Geschick-Schicken (historia, destino, envío), la determinación del ser en varias las épocas presupone la indivisibilidad de un envío originario del ser y una unidad de destino que, aunque no tenga la unidad de una totalidad y no esté ordenado teleológicamente, conserva trazas de tal esquema en la medida en que todavía es parte del mismo sistema de entrega (cf. Derrida 2017 143). La noción de época solo tiene sentido en relación con el destino o el envío reunido del ser y una primera determinación del ser como presencia (Anwasenheit), solo desde esta premisa puede Heidegger afirmar que en la modernidad se establece una nueva relación del ser, los entes y la esencia de la verdad, a saber, el ser de los entes es interpretado como representación. Sin embargo, no se trata de una mera contingencia, si no que de algún modo ya estaba anunciado en el envío del ser como Anwesen:

Si ha habido representación, es quizá porque, justamente (y Heidegger lo reconocería) el envío del ser estaba originariamente amenazado en su ser-en-conjunto, en su Geschick, por la divisibilidad o la disensión (lo que yo llamaría la diseminación). ¿No puede entonces concluirse que si ha habido representación, la lectura epocal que de ella propone Heidegger se convierte, por ese hecho, en problemática de entrada, al menos como lectura ordenadora (cosa que ésta pretende ser también), si no como cuestionamiento abierto de aquello que se presta a ser pensado más allá de la problemática e incluso más allá de la cuestión del ser, del destino conjuntado o del envío del ser? (Derrida 2017 144)

Una época no es la modificación de un ente, pero se anuncia mediante un envío del ser que se desvela como presencia (Anwesenheit). Por tanto, la época de la representación debe pertenecer a la conjunción de un envío más originario. En efecto, si el Geschick del ser no se hubiese anunciado primero como Anwesenheit del ser, ninguna interpretación de la época de la representación llegaría a situarla en la unidad de una historia de la metafísi- 
ca, dicho de otro modo, la condición para que una figura epocal se conforme y se sitúe en el seno de una destinalidad del ser es un envío en conjunción consigo mismo. Esta es el esquema de la lectura historial o destinal que coloca la época de la representación en relación con un envío originario del ser como presencia, y después como representación según las alteraciones en el ser-en-conjunto del mismo envío.

La reinscripción que lleva a término Derrida de la noción de Geschick, está teóricamente expuesta en el envío con fecha 6 de septiembre de 1977 de La tarjeta postal: "[...] voy a aprovechar para clarificar un poco la historia de la adresse, en fin, del Geschick" (Derrida 2001 68-69). Esta recontextualización del vocabulario ontológico al contexto técnico de lo postal, tiene el propósito de deconstruir la reapropiación metafísica que fatalmente acompaña el proyecto heideggeriano de la Destruktion. En efecto, el objetivo de la deconstrucción es localizar la posición de la alteridad o situar cierta exterioridad en el seno de una determinada conceptualidad filosófica -en este caso, la técnica y su contaminación esencial y originaria en relación a un origen prístino incontaminado-, para proceder desde ella cuestionar las intenciones significativas del texto desde sus propias contradicciones. A este respecto, Derrida advierte que ya el mismo planteamiento heideggeriano que niega que haya época sin retirada del ser, no dista mucho del discurso de lo postal, en la medida en que enviar implica también una pausa o ruptura, un retraso y una suspensión. Este servicio postal parece indisociable de la determinación tecnológica y, por consiguiente, de la historia de la metafísica:

Martin [...] vería en la determinación postal una imposición prematura (?) de la techné y por ende de la metafísica (me acusaría, ya lo ves venir, de construir una metafísica de lo postal o de la postalidad); y sobre todo una imposición de la posición precisamente, de determinar el envío del ser en posición, postura, tesis o tema (Setzung; thesis, etc.), gesto que él pretende ubicar, al igual que la técnica, en la historia de la metafísica, y con el cual se daría pie a reflexionar acerca de un disimulo y un retiro del ser en su envío. Allí es donde las cosas son más difíciles: porque la idea misma de retiro (propia de la destinación), la idea de alto y la idea de época en la que el ser se 
retiene, suspende, retira, etc., esas ideas son inmediatamente homogéneas con respecto al discurso postal. Poster, poner en el correo, es enviar "contando" con un alto, un relevo o un plazo suspensivo, el sitio de un cartero, la posibilidad de la desviación o del olvido (no de la represión, que es un momento de custodia, sino del olvido). La epojé y el Ansichhalten que acompasan o dan ritmo esencialmente al "destino" del ser, o su "apropiación" (Ereignis), son el sitio de lo postal, es allí donde adviene y tiene lugar (ereignet diría yo), es allí también donde da lugar y deja advenir. Eso es grave porque tal vez perturba (tal vez) el esquema de Heidegger que sigue siendo "derivativo", perturba al hacer pensar que la técnica, la posición, digamos incluso la metafísica no ocurren, no concurren para determinar y disimular un "envío" del ser (que aún no sería postal), sino que pertenecen al "primer" envío -que obviamente nunca es "primero" en orden alguno, por ejemplo cronológico o lógico, ni siquiera el del logos (por eso no se puede substituir más que en broma la fórmula "en el principio era el logos" por "en el principio era la poste"). (Derrida 2001 69)

Si la metafísica y la tecnología no advienen a fin de encubrir un primer envío del ser originario, ¿quiere esto decir que la metafísica y la tecnología son originarias? Derrida considera la época de la metafísica en su deriva tecnológica desde una economía que sería a la vez más general y originaria que la economía restringida del ser con la que opera la Destruktion heideggeriana. La época de la representación y lo tecnológico no es algo que esté destinado desde el origen y se haga efectivo al final de una serie de épocas en cuya esencia se ha ocultado del pensamiento como el olvido del ser. La técnica siempre ha comenzado, igual que la escritura, ambas, acontecen en el mismo movimiento e introducen la necesidad y la irreductibilidad de inscripción generalizada, es decir, la técnica es más originaria que la diferencia no pensada (Unter-Schied) entre ser y entes o entre una técnica actual y una esencia que radica principalmente en la creación de una red de aplazamientos sin fin:

Si la poste (técnica, posición, "metafísica") se anuncia desde el "primer" envío, entonces ya no existen ni La metafísica, 
etc. (esto intentaré decirlo una vez más, de otra manera) ni siquiera EL envío, sino envíos sin destinación. Pues ordenar las diferentes épocas, etapas, determinaciones, en suma, toda la historia del ser, según la destinación del ser, constituye tal vez el engaño postal más inaudito. (Derrida 2001 69-70)

Derrida piensa lo postal a partir del carácter destinal del ser y no el destino del ser a partir de lo postal (cf. Marrati101), como punto de convergencia de transferencias y correspondencias, además de la posibilidad de toda trópica y la imposibilidad estructural de toda unidad, ya sea "una" historia, "un" destino o "una" metafísica. La crítica de Derrida a las épocas del ser de Heidegger se puede ver entonces como una afirmación de un compromiso continuo con varias historias de la filosofía, si bien puede cuestionarse que las determinaciones de filosofía e historia como el condicionamiento necesario para una filosofía de la historia tal y como se formula en De la gramatología:

Esta historia (como época: época no de la historia sino como historia) es la que se clausura al mismo tiempo que la forma de estar en el mundo que se llama saber. El concepto de historia es el concepto de la filosofía y de la episteme. Aun cuando no se ha impuesto sino tardíamente en lo que se llama la historia de la filosofía, estaba llamado a ello desde el comienzo de esta aventura. (Derrida 2017 360)

El valor de la reunión (legein) y el deseo de lo propio y de lo próximo son recurrentes en un pensamiento escatológico que opera desde un arjé hasta un telos, por su parte, lo postal representa la imposibilidad estructural de toda posibilidad de unidad: "allí donde el envío del ser se divide, desafía el legein, desbarata su destino [...]" (Derrida 2017 144). En "Los fines del hombre" Derrida afirma que este privilegio toca casi todos los aspectos del texto de Heidegger, lo que le lleva a cuestionar que "la distinción entre períodos dados del pensamiento de Heidegger, entre los textos anteriores y posteriores al llamado Kehre, tiene menos pertinencia que nunca" (Derrida 2013 161). La restauración de la esencia (Wesen) con respecto a la restricción metafísica es también el restablecimiento de la dignidad y la proximidad del ser y del hombre, desde toda una metafórica de proximidad y presencia 
inmediata, una metafórica que asocia la proximidad del ser del hombre con los valores de vecindad, voz y escucha. Aquí encontramos la formulación más evidente de lo que para Derrida sigue siendo la pertenencia del pensamiento de Heidegger al ámbito de la metafísica, e introduce la cuestión de si esa supuesta conjunción originaria no será más bien una disyunción que a la postre haga imposible tanto la reunión como el envío a un destino en particular:

Mi cuestión es entonces la siguiente, y la formulo demasiado de prisa: allí donde el envío del ser se divide, desafía el legein, desbarata su destino, ¿no se hace, por principio, discutible el esquema de lectura heideggeriano, no queda historialmente deconstruido, y deconstruido en la historialidad que sigue implicando ese esquema? Si ha habido representación, es quizá porque, justamente (y Heidegger lo reconocería) el envío del ser estaba originariamente amenazado en su ser-en-conjunto, en su Geschick, por la divisibilidad o la disensión (lo que yo llamaría la diseminación). (Derrida 2017 144)

No sería un medio de reunir un punto de origen y un punto de llegada preexistentes, no habría modo de "sumergir todas las diferencias, mutaciones, escansiones, estructuras de regímenes postales en una oficina central de correos" (Derrida 2001 66). Se trata de un envío que no se reúne más que dividiéndose, difiriéndose, un envío pre-ontológico no originario que no constituye unidad ni comienza consigo mismo, aunque nada presente le preceda; un envío que solo emite remitiendo o solo emite a partir de lo otro: "Todo comienza con el remitir, es decir, no comienza" (Ibid. 150). Desde el momento que esa fractura divide de entrada todo remitir siempre hay una multiplicidad de remisiones, huellas que remiten a otras huellas que no tienen la estructura de representantes o de representaciones. Esta divisibilidad o différance es la condición para que haya envío:

[...] una diferencia que no se ordenaría ya con la diferencia del Anwesenheit o de la presencia, o con la diferencia como presencia, una diferencia que no representaría ya a lo mismo o la relación consigo del destino del ser, una diferencia que no sería repatriable en el envío de sí, una diferencia como envío que 


\section{no sería uno, ni un envío de sí. Sino envíos del otro, de los otros.} Invenciones del otro. (Derrida 2017 145)

Pero estas remisiones o "huellas de la différance" no son las condiciones originarias o trascendentales a partir de las cuales Heidegger pretende derivar unos efectos o unas épocas, se trata de remisiones a remisiones de remisiones, en un destino siempre dividido. Entre el Schicken y el Geschick hay una cesura, una brecha, un espacio que difiere, porque enviar implica necesariamente una pausa o ruptura, un retraso, una suspensión, una epojé. Y esto entraña consecuencias catastróficas, en la medida en que lo postal como acontecimiento, y como acontecimiento de la tecnología, siempre se encuentra dividido por la posibilidad del acontecimiento de no llegada. En este contexto, la tecnología se convierte en la huella de una operación que, al tachar todas las configuraciones epocales en las que el ser se destinaría a sí mismo, inscribe de nuevo la instancia que el ser disimula: la "época tecnológica".

El envío postal se encuentra más allá del ser y de su historia, porque no se reúne en su esencia o si se reúne solo lo hace dividiéndose, además, la noción de envío depende del hecho de que una carta siempre puede no llegar. No se trata solo de una posibilidad de relevos, retrasos, anticipaciones o desvíos; se trata de una necesidad constitutiva a la propia estructura del dispositivo telecomunicante, con lo que el acontecimiento del envío no puede de ninguna manera garantizar la llegada: "Sería preciso que en él proporcionara (prácticamente, efectivamente, performativamente), pero para ti, dulce amor mío, inmensa mía, la demostración de que una carta siempre puede -y por ende debe- no llegar a su destino" (Derrida 2001 122).

\section{4· Envío y catástrofe}

En La tarjeta postal Derrida ofrece una realización escritural del Ereignis, cuya temporalidad concuerda con una intuición filosófica de la catástrofe (cf. Rapaport 195), en la medida en que describe un movimiento hacia la alteridad que supone la espacialización del tiempo, impidiendo pensar en el Schicken a partir del Geschick. En efecto, al transponer el vocabulario ontológico heideggeriano dentro del contexto del aparato de una transmisión textual o de una tecnología de la destinación, Derrida puede deconstruir la 
metafísica de la recuperación del ser que acompaña al proyecto de la demolición heideggeriana describiendo un doble movimiento que es a un tiempo de alejamiento crítico y máxima fidelidad a un proyecto que suscribe y en el que se inscribe.

Dada la evolución del mensaje en camino, la noción de strophe adquiere un sentido apostrófico o catastrófico, porque donde para Heidegger hay unidad de destino, Derrida encuentra diseminación y adestinación; donde para uno hay apóstrofe, para el otro fatalmente el resultado del envío será catastrófico. Y es así porque solo es posible dirigirse al otro sobre la base de una interrupción, una cesura, la separación sin la que el otro no sería otro. La interrupción de la dirección es la dirección misma, solo siendo posible que una carta no llegue nunca a su destino, es como la carta puede llegar a su destino. Si todo empieza con un envío, este envío debe ser divisible y plural, no hay envíos simples solo envíos sin destinos seguros, como no hay una sola metafísica, ni Oficina postal central: "Poner en el correo, es enviar asumiendo un relevo, un plazo, la misma posibilidad de la desviación o del olvido" (Derrida 2001 68-71). Tan pronto como la llegada o la identidad de la tarjeta es afirmada, hay indecibilidad, o dicho en el célebre sintagma heideggeriano "hay la différance".

Una consecuencia del proceso de transmisión de los mensajes es el siguiente, receptor y remitente devienen efectos de los erráticos giros y trayectos (cf. Marrati 106) al tiempo que la red postal se inviste de implicaciones existenciales sobre le diálogo entre uno mismo y el otro. De este modo, la problematización de la relación entre Heidegger y Derrida no es gratuita, sino connatural al envío mismo del pensamiento de Heidegger cuando adquiere la forma de una carta que reviste, a un tiempo, consecuencias apostróficas y catastróficas. En efecto, Derrida reelabora la historia intelectual desde la perspectiva de una genealogía deconstructiva que violenta la habitual percepción del tiempo y el juego de influencias y correspondencias, sugiriendo un retardo en las relaciones de sucesión que trastoca la propia diacronía. Para ilustrar su relación con sus predecesores, ensaya en "Envíos" una serie de variaciones, auténticas "realizaciones escriturales", a partir de un grabado del siglo XIII en el que Platón se encuentra a espaldas de un Sócrates sentado y aparentemente dictando lo que este último está escribiendo: 
La carta establece en contrato lo siguiente, así de tonto, tal parece: Sócrates viene antes de Platón, hay entre ellos -y en general -un orden de generación, una irreversible secuencia hereditaria. Sócrates está antes, no delante sino antes de Platón, y por ende detrás de él, y la carta nos ata a ese orden: he aquí cómo orientarse en el pensamiento [...] (Derrida 200128 )

La estrategia de Derrida enviando siempre la misma tarjeta postal con diferentes inscripciones reitera la cualidad paranomásica de la escritura, en la medida en que en la repetición hay diferencia, y la misma tarjeta se espacia estableciendo, por un lado, una correspondencia entre el tiempo simultáneo de lo sincrónico, de lo idéntico, y, por otro, de lo diacrónico, de aquello que se despliega y difiere sobre el pasado, el presente y el futuro. En resumidas cuentas, el envío no puede ser desvinculado de la duración de su ser transmitido, es decir, es siendo escritura. La historia de la escritura de Derrida, como versión textual de la historia del ser de Heidegger, es un intento de dar cuenta de la radicalidad de la temporalidad del lenguaje.

A su vez, la imagen de la tarjeta se ofrece como una idea que desafía los supuestos de una historia intelectual genealógica y los conceptos solidarios de transmisión, influencia y legado. "Envíos" propone una interpretación del presente como différance primordial de un origen absoluto (arjé), pero también de un fin absoluto (telos), como una realización escritural de la teoría esbozada al final de La introducción a "El origen de la geometría":

La Diferencia originaria del Origen absoluto que puede y debe indefinidamente, con seguridad apriórica, retener y anunciar su forma pura concreta como el más allá o el más acá que da sentido a toda genialidad empírica y a toda profusión fáctica, tal vez sea lo que siempre se dijo bajo el concepto de "trascendental", a través de la enigmática historia de sus desplazamientos. Trascendental sería la Diferencia. Trascendental sería la inquietud pura e interminable del pensamiento dispuesto a "reducir" la Diferencia, superando la infinitud fáctica hacia la infinitud de su sentido y de su valor, es decir, manteniendo la Diferencia. Trascendental sería la certeza pura de un pensamiento que, no pudiendo aguardar el telos que se anuncia ya no es avanzando sobre el Origen que se reserva 
indefinidamente, jamás debió llegar a saber que estaría siempre por venir. (Derrida 2000 162)

Por tanto, otra consecuencia de la transposición del envío a la tecnología de lo postal es la de permitir a Derrida reconsiderar la noción de historia intelectual, como genealogía de transferencias en correspondencia con una representación de la historia de la filosofía, a partir del envío del ser transmitido a través de la conciencia autobiográfica de los diversos pensadores, no tanto como una matriz de relaciones conceptuales, sino como una genealogía donde el propio ser del filósofo tiene lugar como lo que ha sido destinado. Así, el envío del ser no es solo recibido en diferentes épocas como el desvelamiento de la verdad, sino también como un acontecimiento vivenciado de forma autobiográfica. La temporalidad de esta genealogía se constituye como una correspondencia o apropiación de momentos donde la filiación es, al mismo tiempo, establecida y rota. Este es el acontecimiento de una historia intelectual en la que el Ereignis como apropiación y desapropiación tiene lugar, y esboza la historia de un destino que frustra las expectativas de los historiadores de la filosofía para los que aparece teleológicamente predeterminada en un aparato conceptual que ya había comenzado a ser demolido por Heidegger:

[...] mi tarjeta postal lo trastoca todo, ingenuamente. Alegoriza, en todo caso, lo catastróficamente no sabido de la orden. Por fin se empieza a no entender qué quiere decir venir, venir antes, venir después, prevenir, volver a venir - y la diferencia de generaciones, y luego heredar, escribir su testamento, dictar, hablar, escribir bajo dictado, etc. (Derrida 2001 29)

Lo que caracteriza esta deconstrucción es una especial atención al acontecimiento como catástrofe que ocurre desde el mismo instante en que Derrida recibe la carta de Heidegger, cuando su mensaje ha sido entregado a pesar de haberse desviado de su destino. Como ya apuntamos, esta aparente paradoja se explica porque tan pronto como el envío es recibido hay la différance:

Todo lo anterior no debe llevar a creer que no existe comunicación telefónica alguna entre el fantasma de Heidegger y yo, entre algunos otros y yo. Al contrario, mi red de conexiones, y aquí tienen una prueba de ello, 
se halla más bien saturada, y haría falta más de una central telefónica para digerir el exceso. (Ibid. 28-29)

Los firmantes y destinatarios difieren de un envío a otro, ni los primeros se confunden necesariamente con los remitentes, ni los destinatarios se identifican forzosamente con los receptores. Ambos son meros efectos de tales errancias, es decir, no preexisten en sendos extremos como agentes que se sirven de lo postal para establecer una comunicación entre conciencias, en primer lugar porque tal predestinación de igual a igual contradice efectivamente la différance que lo postal establece. Y de un modo más fundamental, porque escribir, firmar, comunicar un mensaje tiene lugar bajo la condición necesaria de la posibilidad misma del extravío, como ya señalamos. En el caso del remitente se produce además la paradoja estructural de que las cartas articulan el acontecimiento de la separación de los corresponsales, así como de la diseminación de las nociones de reunión y apropiación implícitas.

Un nuevo efecto de la economía de lo postal será la expresión de la típica ambigüedad derridiana en relación a Heidegger. Las tarjetas postales no son solo apo-stróficas (un alejamiento de), sino cata-stróficas (una vuelta). La tarjetas se alejan de ambos y la correspondencia deviene problemática, como sus respectivas preguntas acerca de la temporalidad del envío de la inscripción y su ubicación o desubicación, la unidad o la diseminación, el destino o la errancia. En la medida en que su escritura es muy consciente de la tecnología que sustenta la correspondencia entre ambos, Derrida se mantiene próximo a los postulados heideggerianos. Sin embargo, se aleja de Heidegger porque su correspondencia está siendo remitida atrás en el tiempo, hacia un destino que la tarjeta no puede nunca alcanzar, un destino sin el que la filosofía sería discontinua, y nuestra capacidad para pensar depende de esa habilidad para remitirnos a los muertos, muertos como Platón, Aristóteles o el propio Heidegger:

La telefonista norteamericana me pregunta si acepto un "collect call" (léase: llamada por cobrar) de parte de Martin (y pronuncia Martín o martini) Heidegger. Como suele suceder en esas situaciones que me son familiares, pues yo mismo tengo que llamar collect, oía voces que creí identificar del otro lado de la línea intercontinental: me están escuchando y están vigilando 
mi reacción. ¿Qué va a hacer ante el ghost o el Geist de Martin? No puedo resumir aquí toda la química del cálculo que rápidamente me llevó a rechazar la llamada ("It's a joke, I do not accept") después de haber hecho repetir varias veces el nombre de Martini Heidegger, con la esperanza de que el autor de la broma se diera por fin a conocer. En suma, ¿quién paga? ¿el remitente o el destinatario? ¿quién debe pagar? (Id.)

En efecto, las filiaciones que Derrida trata de superar regresan siempre desde el interior de los textos como susurros espectrales, fantasmas del otro que asedian el texto, lo recrean, lo repiten, lo reescriben, lo resucitan, lo retractan y lo restituyen, para ofrecerlo, al cabo, "como si fuera otro", vagando a través de las sendas de lo impensado o lo que ha sido evitado o forcluido u olvidado. La escritura siempre es su propio fantasma. La escena de la filiación intelectual adquiere en Derrida el significado de un acontecer ontológicamente intertextual situado en el espacio de las diferencias entre la memoria y la imaginación poética, entre la verdad archivada y el libre juego de las interpretaciones. Solo por apropiación de Heidegger puede Derrida demoler la historicidad de tal apropiación. Pero para que esto suceda, el destinatario del envío de Derrida debe no solo ser retenido, sino también borrado, solo así puede ser inscrito en la problemática de la revelación y retirada del ser. Siendo así que la carta o la tarjeta enviada a Heidegger se extraviará, por eso la filosofía de Heidegger no alcanzará su destino de ir "más allá" de la filosofía, reclamado por la Destruktion. Una consecuencia de esta reflexión es que por medio de la herencia y la aceptación del legado del pensamiento heideggeriano, a través del que el ser ha sido "despachado", Derrida no solo lleva adelante lo que Heidegger reconoce como la demolición de la metafísica y la revelación de la problemática temporal, si no que desmantela los fundamentos de una historia intelectual. La misma herencia del legado de Heidegger es lo que comprende la deconstrucción de la correspondencia entre legador y legatario. Por lo tanto, lo que caracteriza a esta deconstrucción es su especial atención al acontecimiento, no meramente como Ereignis, sino también como catástrofe. 


\section{$5 \cdot$ Conclusiones}

Hemos ideo viendo varias consecuencias de pensar el Ereignis desde la economía de lo postal. Pensar el ser para Heidegger consiste en reconocer la estructura originaria subyacente en cada expresión histórica, esto es, las huellas de la destinación que configuran y singularizan cada época. De modo que "época" nombra al ser en relación a su descubrimiento de los entes que organiza nuestra relación con ellos. Esto presupone la indivisibilidad del envío originario y necesariamente un ser "transepocal". En efecto, el dar se manifiesta con respecto al ser como destinar y como unidad de todas las destinaciones del ser como Anwesen. De lo anterior se colige que Heidegger puede solo destacar épocas y, entre ellas, la época de la representación a partir de esta unidad originaria. Esta unidad originaria u origen único, junto al esquema teleológico que soporta, se ha visto deconstruida como consecuencia de la transposición del envío ontológico a una tecnología de la trasmisión.

En primer lugar, la lectura derridiana detecta un hiato, localiza una pausa entre el Schicken y el Geschick, que difiere en la medida en que el envío no puede ser liberado de la duración de su ser transmitido. Esta différance, entendida como temporización y espaciamiento, se convierte en la condición de posibilidad de todo envío. En segundo lugar, lo postal se encuentra dividido por la posibilidad del acontecimiento de la no llegada, que desmantela la estructura teleológica del envío originario. Ahora bien, si lo postal representa la imposibilidad estructural de toda unidad, de todo legein, se colige que también implica la negación de un destino, de una historia o de una metafísica. Se comprende entonces el compromiso de Derrida con varias historias de la filosofía posibles o la negación de una única metafísica de raigambre platónica.la(s) historia(s) de la escritura de Derrida deviene (n) una versión textual de la historia del ser de Heidegger donde se pone de manifiesto la huella de una operación que tacha las configuraciones epocales en la que el ser se destina a sí mismo e inscribe la instancia que disimula: "la época tecnológica".

La principal consecuencia de lo anterior, en vistas a dilucidar la correspondencia entre Heidegger y Derrida, consiste en que el proceso de transmisión violenta el juego de influencias y correspondencias, desafian- 
do el supuesto de una historia intelectual en términos genealógicos y la batería de conceptos solidarios de influencia y legado que apareja. En efecto, Derrida recibe el envío de Heidegger y lo repite. En la repetición, lo mismo regresa como otro. El envío es siempre otro en la medida en que no se construye sobre su auto-relación, ni se reúne consigo mismo. Es otro de su origen y de su destino, porque la cesura que hace posible la transmisión y la comunicación con el otro, subordina la relación entre el remitente y el destinatario al mismo proceso de transmisión, una correspondencia telemática compuesta de transmisiones, remisiones, reenvíos, traducciones y transferencias que anuncian una conjunción catastrófica, imposible, entre Derrida y un Heidegger espectral siempre por venir.

\section{6-Bibliografía}

Casey, S. Edward. "Origin(s) in (of) Heidegger/Derrida". The Journal of Philosophy, 81/10 (1984): 601-610.

Derrida, Jacques. La tarjeta postal, trad. cast. Haydée Silva. México: Siglo XXI, 2001.

Derrida, Jacques. La escritura y la diferencia, trad. cast. Patricio Peñálver. Barcelona: Anthropos, 2012.

Derrida, Jacques. Márgenes de la filosofía, trad. cast. Carmen González Marín. Madrid: Cátedra, 2013.

Derrida, Jacques. Heidegger: The Question of Being \& History, trad. ingl. Geoffrey Bennington. Chicago: The University of Chicago Press, 2016.

Derrida, Jacques. Psyché. Invenciones del otro, trad. cast. Mónica B. Cargnolini et ál. Avellaneda: Ediciones La Cebra, 2017.

Gaston, Sean. Jacques Derrida and the Callenge of History. Londres: Rowman \& Littlefield International, 2019.

Heidegger, Martin. Aportes a la filosofía. Acerca del evento, trad. cast. Dina V. Picotti C. Buenos Aires: Editorial Biblos, 2011a.

Heidegger, Martin. La historia del ser, trad. cast. Dina V. Picotti C. Buenos Aires: El hilo de Ariadna, 2011b.

Heidegger, Martin. Tiempo y ser, trad. cast. Manuel Garrido. Madrid: Tecnos, 2013a

Heidegger, Martin. Identidad y diferencia, trad. cast. Helena Cortés y Arturo 
Leyte. Barcelona: Anthropos, 2013b.

Heidegger, Martin. Caminos de bosque, trad. cast. Helena Cortés y Arturo Leyte. Madrid: Alianza Editorial, 2015.

Marrati, Paola. Genesis and Trace. Derrida Reading Husserl and Heidegger, trad. ingl. Simon Sparks. California: Stanford University Press, 2005.

Peretti della Rocca, Cristina de. "'Ereignis' y 'Différance'. Derrida, intérprete de Heidegger. Logos: Anales del Seminario de Metafísica 12 (1977): 115132.

Rapaport, Herman. Heidegger \& Derrida. Reflections on Time and Language. Nebraska: University of Nebraska Press, 1991.

Rubín, Abraham. "Heidegger desgarrado. El papel de la diferencia en la concepción de "Ereignis"'. Revista de Filosofía 37 (2013): 31-54.

Spinosa, Charles. "Derrida and Heidegger: Iterability and Ereignis". A Companion to Heidegger, eds. Hubert L. Dreyfus \& Mark A. Wrathall. Massachusetts: Blackwell Publishing, 2005. 484-510.

Wood, David. The Deconstruction of Time. Evanston: Northwestern University Press, 2001. 